\title{
THREE CASES OF TRAUMATIC PULSATING EXOPHTHALMOS*
}

\author{
BY \\ Dr. Dumitru Lazarescu and Dr. Eugenia lazarescu \\ IASSY, ROUMANIA
}

OPHTHALMOLOGICAL CLINICS AT IASSY. DIRECTOR : PROFFSSOR ELENA PUSCARIU

Clinical cases often occur in series. Between July, 1928, and September, 1929, we had the opportunity of examining, at the ophthalmological clinics at Iassy, three cases of pulsating exophthalmos, all of traumatic nature; one of them due to lesions occasioned by a bullet located intracranially, as shown by X-rays ; one to fracture of the base of the skull and one to contre-coup.

\section{Case I}

T. G., male, aged 14 years, a war orphan from the city of Vaslui, entered the ophthalmological clinics of Iassy on July 12, 1928, with proptosis of the left eye and various nervous disturbances.

The history of the condition was as follows : On May 21, 1928, he was accidentally shot by a revolver in the lower left eyelid. He was taken to the hospital at Vaslui in a comatose state. A week later he was transferred to the surgical section of the Hospital St. Spiridon at Iassy. A radiograph of the skull showed the bullet in the occipital region. Two weeks after the injury the oedema of the right eye lessened ; the boy began to move this eye and to recognise surrounding objects. According to the statement of his mother the injured eye had always been exophthalmic before the accident. With return of consciousness the boy complained of hearing a mill-like noise in his head. Professor.Elena Puscariu diagnosed the case as pulsating exophthalmos due to arterio-venous aneurysm.

Examination of the general condition showed the boy to be well developed. There was almost complete deafness, with right facial palsy and paralysis of the left third cranial nerve, superficial sensibility was disturbed and both knee-jerks were exaggerated; ataxia was present with athetoid movements in the left arm. Babinsky's sign was present in the right foot. The mental condition was peculiar, the boy laughing without reason; the abdominal and cremasteric reflexes were exaggerated, there was no disturbance cf the sphincters. The right eye was found to be normal.

Examination of the left eye showed the upper eyelid to be violet coloured with intense collateral circulation; the globe was proptosed almost out of the socket and was motionless; chemosis

- Cases 1 and 2 were shown at a meeting of the Medical Society of Iassy in 1929. 
present in the lower half; the cornea, being partly covered by the swollen conjunctiva, showed infiltrations and dilated vessels, but did not stain with fluorescein. (Fig. 1.)

The lower lid was much swollen and showed in its middle third the scar of the bullet wound. The bones of the orbit appeared uninjured. Vision in the right eye was normal, the left eye was blind. The tension of the right eye was $21 \mathrm{~mm}$., that of the left. $27 \mathrm{~mm}$. The exophthalmos measured $14 \mathrm{~mm}$. in the right eye and

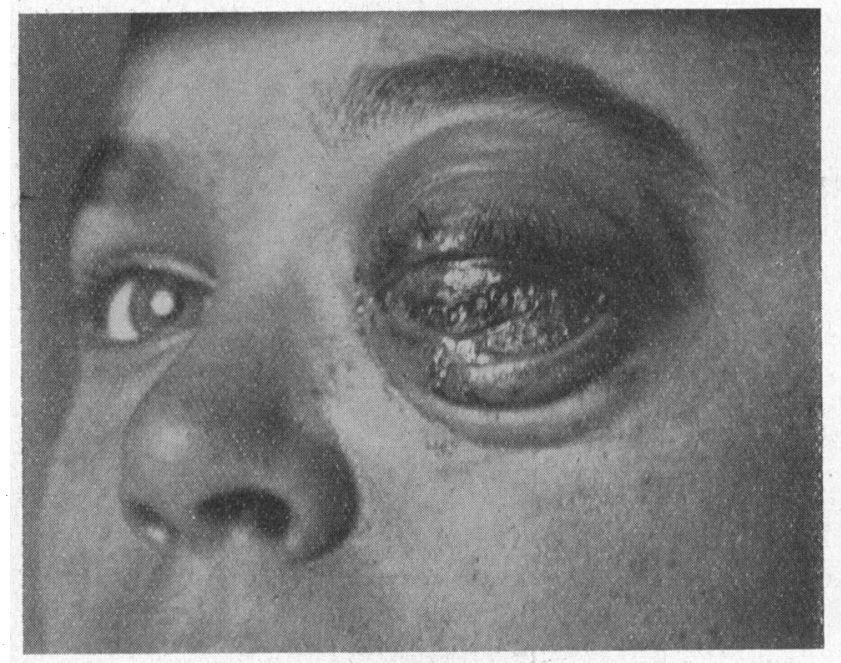

Fig. 1.

$30 \mathrm{~mm}$. in the left. Pulsation was well marked in the upper-inner angle of the orbit, and could be felt as an almost continuous quivering. A loud bruit could be heard at the left temple synchronous with the cardiac systole and sounding like the gush of steam from an engine; compression of the left carotid entirely stopped this noise.

On July 17,1928 , an attempt was made to sew the lids together and to ligature the ophthalmic vein, but had to be given up on account of severe haemorrhage, which could only be controlled by leaving. a forceps in position for three days. The boy was discharged complaining of retro-orbital pain.

On November 10,1928 , he returned to the clinic. The exophthalmos now measured $33 \mathrm{~mm}$.' Pulsation, thrill and bruit as before, the bruit being stopped by compression of the left carotid. The cornea was opaque and ulcerated; hearing had returned almost to normal in the right ear. The bruit could be heard as far back as the occiput with its point of maximum intensity in the temple.

Neurological examination showed the left eyebrow and labial 
commissure to be raised, movements of the right face reduced. Movements of adduction, abduction and extension of the fingers of the right hand abolished; movements of the sole of the right foot absent ; flexion at the right hip reduced. The boy had to have support when walking and stepped on the outer side of the foot and tips of the toes.

There was remarkable hypotonicity of the right foot flexor muscles; the popliteal cavity had disappeared, the leg making on the thigh an angle opening forwards contrary to the normal. The eyeball was motionless, its sensibility very much reduced, that of the cornea practically absent. The knee-jerks were exaggerated, especially the right. Clonus was present in the right foot and Babinsky's sign as at first. The boy's mental condition was still peculiar, he laughed without reason. The bullet must have produced an injury to the pyramidal tract causing a right hemiplegia; probably caused a direct injury of the optic nerve and the third cranial nerve, the trigeminal and the Gasserian ganglion. Further treatment in this case was refused and the boy left hospital.

\section{Case 2}

C. V., male, aged 34 years, a railway worker in Ocnitza, Basarabia, attended the medical station of the railway on March 23, 1929, with right-sided pulsating exophthalmos. In November, 1927 , he had suffered a head injury from some planks while he was uncoupling two waggons. He was picked up unconsciaus and taken to hospital. On the way he came to his senses and found that he was bleeding from the nose and ear. In this state he was admitted to the surgical clinic; next day he presented left facial palsy and convergent strabismus of the left eye, with consequent diplopia and intense headache. 'The headache gradually diminished, but from the start he had diminished hearing on the right side, and complained of a windy noise in the head which annoyed him day and night. Lumbar puncture was performed on admission and an ice bag placed upon the head.

He left the clinic on December 18, 1927, showing facial palsy and left external rectus paralysis, with slight diminution of the right palpebro-ocular sulcus. In March, 1928, he was admitted to the medical clinic for massage and electrical treatment, which cleared up the facial palsy and diplopia. He went back to work in April, 1928, though still troubled by the noise in his head. After a month on duty the patient found the noise insupportable and at this time the exophthalmos appeared on the right side; this increased rapidly and was made worse by coughing, sneezing and lowering of the head. The measurements were (Hertel) right eye, $21 \mathrm{~mm}$., left eye, $11 \mathrm{~mm}$. Right eyeball proptosed and lids slightly swollen. (Fig. 2.) 
The swelling passed over the end of the eyebrow and involved the temple. The right palpebro-ocular sulcus was replaced by a swelling which was most marked at the upper-inner angle; the inferior sulcus was slightly diminished, the palpebral aperture slightly stretched and reduced in height. Dilated, sinuous veins

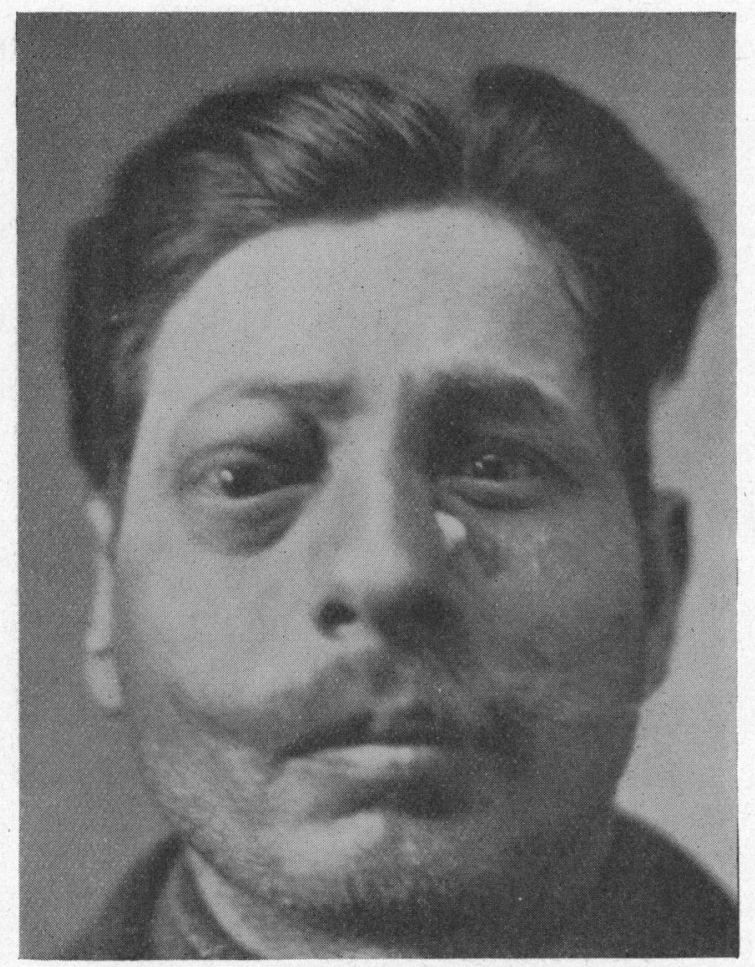

FIG. 2.

were to be felt at the upper-inner angle of the orbit; the swelling pulsated synchronously with the radial pulse and a thrill could be felt. On retracting the eyelids the conjunctiva appeared congested and covered with dilated vessels. The right cornea was clear, but the corneal reflex was diminished; the pupil was irregular, synechiae being present. The pupil diameter was $3 \mathrm{~mm}$. on each side and the reactions were normal.

The visual acuity was R., 0.7 ; L., 1 . The tension was R., $20 \mathrm{~mm}$., L., $18 \mathrm{~mm}$. (Schiötz). The left visual field was normal while that on the right side was diminished between 30 and 50 degrees. Examination of the fundus showed a blurred right disc with distended veins and arteries scarcely perceptible. The left 
fundus was normal. Retinal tension (Bailliart), $30 \mathrm{~mm}$. and $70 \mathrm{~mm}$. The ocular movements were normal, there was no diplopia and no anaesthesia. A marked bruit was heard with maximum intensity at the inner canthus, but propagated to the temple. Lowering the head accentuated the exophthalmos. Rest in bed led to a slight diminution in the exophthalmos, and digital compression of the right carotid led to a cessation of the noise in the head and the patient went home with instructions as to the com-

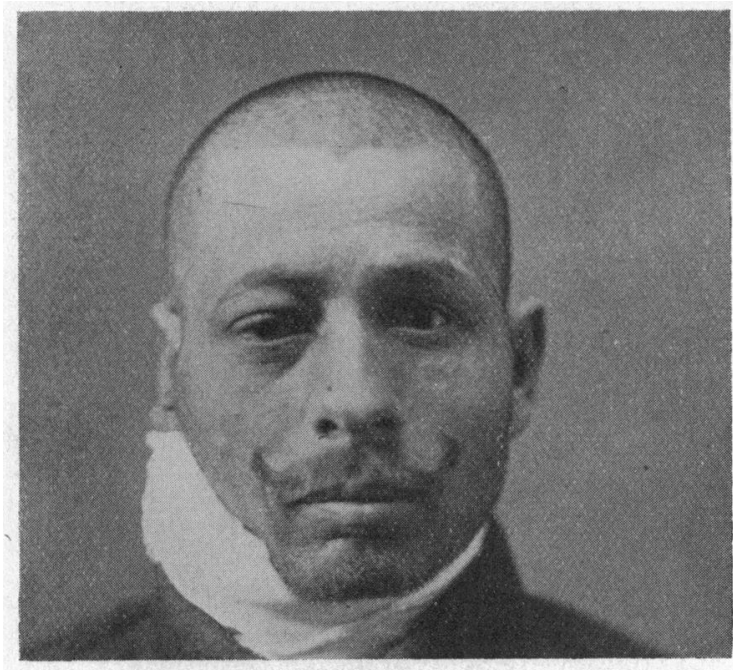

Fig. 3.

pression of his carotid. The general condition was normal; heart, normal; blood-pressure (Pachon), 12.5 and 5.5 . Hearing was diminished on the right side from injury to the ear. The Wassermann reaction in the blood and cerebro-spinal fluid was strongly positive. Urine, normal, blood urea, 0.41 .

On April 11, 1929, the right internal carotid was ligatured under local anaesthesia with novocaine, adrenalin and morphine, subcutaneously by Professor Tanasescu. The wound healed by first intention, the bruit completely disappeared; the exophthalmos measured $19 \mathrm{~mm}$. and the tension $17 \mathrm{~mm}$. A fortnight after operation the exophthalmos measured $16 \mathrm{~mm}$ in the right eye and $11 \mathrm{~mm}$. in the left; the vision was normal in each eye, with the field diminution as on the previous examination. (Fig. 3.)

On leaving hospital the veins in the upper-inner angle of the right orbit could no longer be felt, the vascularity was much diminished. A final examination on September 8, 1929, showed normal acuity of vision in each eye; exophthalmos, R. $13 \mathrm{~mm}$., 


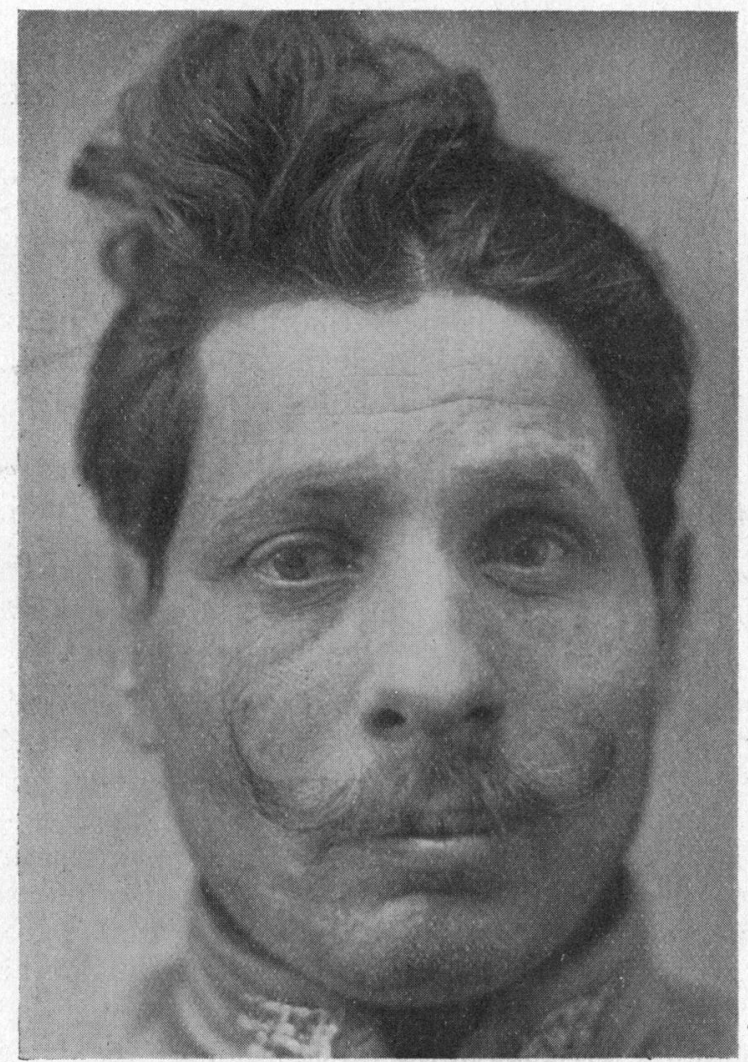

Fig. 4.

L. $11 \mathrm{~mm}$.; visual field in the right eye normal ; bruit, completely disappeared. Slight anaesthesia of the right face is his sole disability; he is on full work and has no discomfort of any kind. He was advised to continue antiseptic treatment. (Fig. 4.)

\section{Case 3}

An electrician, aged 19 years, came to the eye disease clinics at Iassy on August 18, 1929, presenting exophthalmos on the left side. While at work in a building the patient fell on to a cement floor from a height of 4 metres; according to the report of his mates he had fallen on his feet while his head struck the wall of the building. The accident occurred on July 1,1929 . He was picked up unconscious and taken to the surgical section, where he was detained until July 5 , with a contusion of the left orbital region and chin. On admission he had epistaxis and blood discharge from the ear; on regaining consciousness he was found to have slightly 
diminished hearing on the left side; the left eyelids were swollen and ecchymosed. There was some pain in the left orbit which was treated by cold compresses. He also complained of loss of smell and that the sense of taste was dull on the left side of the tongue. The local swelling quickly cleared up and he was discharged with very slight proptosis. After leaving hospital he had vomiting and bleeding from the left nostril and he came to the eye clinics.

He was well developed, the left superior palpebral sulcus was obliterated; the left eye was exophthalmic, and the bulbar conjunctiva was appreciably injected; the eye movements were not affected and no abnormality could be felt in the bones of the orbit. The right eye was healthy. His visual acuity was : left eye, $\frac{1}{3}$; right eye, 1. Exophthalmos measured, left, $19 \mathrm{~mm}$., right, $14 \mathrm{~mm}$. The tension in the left eye was $20 \mathrm{~mm}$., that in the right, $17 \mathrm{~mm}$. General blood pressure was, maximum 8 , minimum 5, measured in the brachials.

The blood Wassermann reaction was negative.

The patient complained of a noise in his head like the gush of steam from an engine from the time that he recovered consciousness; this noise had increased rather than diminished since that date. On auscultation, a bruit was heard all over the left temple with its maximum intensity over the inner end of the eyebrow. On palpation at the inner angle of the orbit a slight pulsation could be felt synchronous with the radial pulse; both pulsation and the noise in the head were controlled by digital compression of the carotid and the man went home to practise compression for himself until such time as he could be admitted for operation.

On September 29, 1929, under general narcosis, he had his left internal carotid tied by Professor Hortolomei. The wound healed by first intention and the after course was uneventful except for some vomiting and slight agitation. Four days after the operation a slight right hemiparesis was noted with right facial palsy, the knee-jerk on the right side was exaggerated, there was no anaesthesia, but all movements, including the opposition of the thumb (Babinsky) were executed with difficulty. The noise in the head was noted twice for a few moments and then disappeared completely; the conjunctival injection cleared up immediately and a fortnight after the operation the exophthalmos measured $15 \mathrm{~mm}$. in the left eye and $14 \mathrm{~mm}$. in the right; the hemiparesis persisted for more than a month.

The visual acuity showed no improvement and there was slight contraction of the field in an upward direction. Hearing remained diminished in the right ear. The man was transferred to the neurological clinic for treatment of the hemiparesis. It should be mentioned that he was an old case of trachoma with much scarring of the conjunctiva. 
In these cases the exophthalmos appeared immediately after the trauma in the first and third cases and after twenty days in the second. Poullard, Boussi and Prosper Vail record a case in which this sign appeared two months after the injury. In our first two cases the pulsation was very obvious to the finger while in the last case it was hardly appreciable except when the man strained. Delore, Aurand and Roland speak of a case of arterio-venous aneurysm in which this sign was completely absent. In most cases this sign can be observed by watching the patient in profile. The pulsations are synchronous with the radial pulse. In each of our cases the ocular tension in the exophthalmic eye was raised. Rochon-Duvigneaud and Varere consider that these tises of tension may almost reach the level of glaucoma. Bailliart has shown that venous pressure is raised in these cases of pulsating exophthalmos while arterial pressure is lowered. In some cases there is remarkable hypertension in the central artery of the retina. When the carotid is torn in the cavernous sinus there is no difference between the minimum and the venous pressure on the exophthalmic side. All patients notice and complain bitterly of the noise in the head. Very occasionally the noise can be heard at a distance without need of auscultation; its maximum intensity is usually in the temple, it is synchronous with the pulse and it is sometimes accentuated by efforts such as stooping and straining. Le Fort thinks that the bruit is intermittent in arterial aneurysm. Local vascular engorgement is usually well marked and neuroparalytic keratitis may occur from damage to the ciliary nerves or ganglion; in some cases the optic nerve is damaged and the eye may be blind. Le Fort gives 44 cases of pulsating exophthalmos with loss of sight, out of 53 cases; in such cases ligature of the carotid usually does not lead to any improvement in visual acuity.

In 41 autopsies, Cauchoix found in 15 cases arterio-venous aneurysm without an actual tear in the arterial wall, in two cases a circumscribed aneurysm of the ophthalmic artery and in six cases dilatation of the sinus was found as well as of the ophthalmic vein. Nida thinks that in these cases of arterial lesion the difference between arterial and venous pressure is nil.

Pulsating exophthalmos may occasionally be due to tumours or athęromatous conditions but the most common cause is injury; either head injury or local orbital injury from penetrating foreign bodies; in these latter cases the value of an X-ray photograph is apparent. Palliative treatment by injections of lactate of iron has given no good results; at the present time ligature of the common or internal carotid artery gives the best hope of amelioration. Such an operation may be followed by hemiplegia, this being due possibly to sepsis or ischaemia. Le Fort, in 1879 , gave a 45 per cent. mortality after this operation. Siegriest in 1900 found a mortality 
of 38 per cent. in 71 cases. De Fourmestraux (Thesis, Paris) in 1908 found a mortality of 21 per cent., which diminution he ascribes to improvement in aseptic technique. Preliminary digital compression of the carotid is recommended before operation in order to try and establish sufficient collateral circulation and so diminish the liability to nervous complications. Cerebral accidents occur in 10 per cent. of cases after ligature of the carotid. The percentage of cures after ligature of the internal carotid should be 63 per cent. ; in cases where ligature of both carotids was necessary the number of cures diminished to 25 per cent., with a mortality of 15 per cent., which fatality is less likely to occur when some lapse of time has separated the two ligature operations. Some authors such as Woodward, Szimanowski, Lazarew, Bodon, Dollinger, Wiesinger, Perthes, Sattler, Burghard and Pritchard, Gifford and Jones, Golovine and Schwalbach recommend ligature of the superior ophthalmic vein at the inner angle of the orbit, preceded by tarsorrhaphy; of 15 cases so treated 13 were cured (Cauchoix).

The sequelae of ligature of the carotid may be embolism of retinal arteries (Siegrist, Broca), paralytic strabismus (Watson, Ehremann), and psychological disturbance with or without paralysis (de Lapersonne and Sendral).

Mortality in pulsating exophthalmos is given by Le Fort as $4 \cdot 7$ per cent.; as 7 per cent. by Sattler and as 4 per cent. by Keller; ligature cures the exophthalmos in 57 per cent. of cases, and the vision is good'so long as the optic nerve has sustained no damage.

Of our three patients the first refused surgical treatment; he will probably get a perforation of his cornea due to neuro-paralytic keratitis and infection, which may lead to death through meningitis, or even to profuse and uncontrollable haemorrhage. The other patients gladly accepted operation, with a satisfactory result in each case. We think that the hemiparesis in the last patient which occurred four days after the operation was probably due to cerebral ischaemia.

Our second patient had the operation performed under local anaesthesia and was very docile during and after the operation: we believe in this form of narcosis for this class of case, as the patient can furnish indications on the effect of the ligature; we have found that the subcutaneous injection of morphine $0.03 \mathrm{ctg} \dot{r}$. as an adjuvant to the local anaesthetic is helpful.

We believe that post-operative nervous complications are closely connected with the lapse of time that occurs between the appearance of the exophthalmos and the surgical intervention; the longer this is the better the chance of a collateral circulation being developed. The importance of these complications cannot be overlooked and we must remember that a hemiplegia may occur; 
if this happens after ligature of the left carotid there will be a rightsided hemiplegia which will be a severe handicap to the future wage-earning capacity of the individual.

\section{REFERENCES}

Cauchoix. Considérations sur les ligatures vasculaires dans le traitement de l'exophtalmos pulsatile. Rev. de Chirurg., 1921.

- Considérations sur les formes anatomo-cliniques et sur le traitement de l'exophtalmos pulsatile. Soc. franc. d'Ophtal., November, 1922.

Delore, Aurand and Rolland. Exophtalmie spontanée non pulsatile par aneurysme artério-veineux de la carotide interne et du sinus caverneux. Echec de la ligature de la carotide primitive. Ligature de la carotide interne. Guérison. Soc. d'Ophtal., Lyon, May, 1928.

Esteban, Mario.-Exophtalmie pulsatile bilaterale. Arch. de Oftal. Hisp.Amer., July, 1928.

Fourmestraux, de.-Les accidents cérébraux et oculaires consécutifs à la ligature de la carotide primitive. Thése de Paris, 1908.

Friess, E. - Contribution a l'étude de l'exophtalmie dans les néphrites chroniques. Thesis, Lyon, 1925.

Fritz.-Zeitschr. f. Augenheilk., S. 186, November, 1917.

Galezowski. - 1875 .

Hay, P. J.- Two cases of exophthalmos due to arterio-venous aneurysm. Trans. Ophthal. Soc. U.K., 1925.

Hoeve, J. van der.-Neder. Ophtal. Gesell., March, 1926.

Henry. - Considé' ations sur l'aneurysme artério-veineux. Thesis, Paris, 1856.

Halle and Poulard.-Exophtalmie pulsatile bilatérale spontanée. Soc. Med. des Hop., 1923.

de Maria, H., and Jorge, J. M.-Arch. de Oftal. Hisp.-Amer., September, 1922.

Lloyd, B. Whitham.-Pulsating exoph thalmos.

Lacroir.-Varicocèle de l'orbite; exophtalmie à volonté. (Ref. Clujul Med., 1920.)

de Lapersonne and Sendral. Resultat de la ligature uni-ou bilaterale de la carotide primitive dans deux cas d'exophtalmos traumatique. Bull. Acad. de Med., T. XXVI. 1919. (Ref. Clujul Med., 1920.)

Lazarescu, D.. and Varticlerne, Georgeta - Traumatic pulsating exoph thalmos. Hemiplegia and bullet in cranium. Medico-Surgical Bulletin, Iassy, 1928.

Lazarescu, E.-Pulsating exophthalmos with fractured base of skull. MedicoSurgical Bulletin, Iassy, 1929.

Lindenmeyer. Exophthalmos nachlassend. Klin. Monatsbl.f. Augenheilk., 1922.

Morelli.-Boll.d'Ocul., 1922.

Moller.-Sur l'aneurysme intracranienne de la carotide. Klin. Monatsbl. f Augenheilk., 1926.

Morax. -1924

Nida.-Soc. d'Ophtal., Paris, 1925.

Ibid.-Sur un cas d'exophtalmie pulsatile. Soc. d'Ophtal., Paris, 1926.

Poulard, Boussi and Prosper Vail. - Exophtalmie traumatique; paralysie de la 6-me paire du coté opposé. Soc. d'Ophtal., Paris, 1922.

Poula:d.-Vol. I.

de Peyrelongue, E., and Baur, F.-Exophtalmie pulsatile; ligature de la carotide primitive; guérison. Arch. d'Ophtal., 1926. Presse Médicale, 1928.

Scotti. - Sobra un caso di esoftalmo pulsatile. Ann. di Ottal. e Clin. Ocul., 1929.

Szokaleski.-L'aneurysme traumatique. Ann. d'Ocul., 1926.

Velter. - Hypertension intra-oculaire dans éxophtalmie pulsatile. Soc. franc. d'Ophtal., Congress 51.

Viloria, Lopez.-Aneurysme carotido-caverneux sans exophtalmie pulsatile. Arch. d'Ophtal., 1929.

Zade.-L'exophtalmie intermittente. Zeitschr. f. Augenheilk., 1929. 